\title{
Lecturas del Quijote en la poesía española reciente: «Yo recordé mi nombre en Barcelona»*
}

\author{
Luis BAGUÉ QuíLEZ**
}

Más de una vez me he preguntado: ¿por qué Cervantes no hizo cuerdo a su héroe?

Santiago Ramón y Cajal, «Psicología de don Quijote y el quijotismo»

\section{Resumen}

Frente a la interpretación romántica que defiende que don Quijote es un personaje heroico e idealista, en la poesía española de finales del siglo XX y comienzos del XXI predomina una visión antiheroica y realista del caballero andante. Por un lado, poemas como «Don Quijote», de Manuel Vilas, y «Primera salida de don Quijote», de Felipe Benítez Reyes, desenmascaran la locura del hidalgo desde una perspectiva grotesca o prosaica. Por otro lado, composiciones como «Morirse de cordura», de Ana Merino, y «Las confesiones de don Quijote», de Luis García Montero, reivindican la cordura, representada por la silueta individual de Aldonza Lorenzo o por la proyección colectiva de Alonso Quijano. A partir de dichos ejemplos, este artículo plantea que el diálogo del Quijote con los lectores actuales se sustenta en la humanización de los personajes cervantinos, en la faceta cotidiana de sus personalidades o en la complicidad que suscitan sus reflexiones.

Palabras clave: don Quijote; poesía española contemporánea; idealismo; realismo; Aldonza Lorenzo; Alonso Quijano.

* Este trabajo es resultado del Programa «Ramón y Cajal» (RYC-2014-15646), del Ministerio de Economía y Competitividad.

** Universidad de Murcia. lbague@um.es / ORCID iD: https://orcid.org/0000-0001-5244-8278. 
Title: Readings of Don Quijote in recent Spanish poetry: «I remembered my name in Barcelona»

\begin{abstract}
Against the romantic interpretation which advocates that Don Quixote is a heroic, idealistic character, the Spanish poetry of the late 20 th century and the early 21 st century has proposed an anti-heroic, realistic view of the errant knight. On the one hand, poems such as «Don Quijote», by Manuel Vilas, and «Primera salida de don Quijote», by Felipe Benítez Reyes, focus on the nobleman's insanity from a grotesque or prosaic perspective. On the other hand, poems such as «Morirse de cordura», by Ana Merino, and «Las confesiones de don Quijote», by Luis García Montero, stand up for sanity, represented by Aldonza Lorenzo's individual character or by Alonso Quijano's collective projection. Based on the above examples, this paper argues that the dialogue between Don Quixote and contemporary readers lies in the humanization of Cervantes' characters, in the quotidian dimension of their personalities or in the complicity generated by their reflections.
\end{abstract}

Keywords: Don Quixote; Spanish Contemporary Poetry; Idealism; Realism; Aldonza Lorenzo; Alonso Quijano.

\title{
Cómo citar este artículo / Citation
}

Bagué Quílez, Luis (2018). «Lecturas del Quijote en la poesía española reciente: "Yo recordé mi nombre en Barcelona"», Anales Cervantinos. 50, pp. 253-278, https://doi. org/10.3989/anacervantinos.2018.011.

\section{EL QUIJOTE EN VERSO: EL EXTRAÑO CASO DEL HIDALGO QUIJANO Y DON QUIJOTE}

Decía Ángel González (2005: 27) que «el lector del Quijote, en el esfuerzo de buscar un sentido a lo que lee, está obligado a poner más de sí mismo que el lector de otros libros, por profundos y complejos que sean». En efecto, la obra abierta de Cervantes es un hervidero de interpretaciones diversas, hipótesis contradictorias y lucubraciones pintorescas. Así pareció preverlo el propio autor en el prólogo de la primera parte, que le concede al «desocupado lector» el beneficio de la duda hermenéutica, a la vez que lo autoriza a ejercer esa modalidad del libre albedrío que es el juicio crítico: «Todo lo cual te esenta y hace libre de todo respecto y obligación, y así, puedes decir de la historia todo aquello que te pareciere, sin temor que te calunien por el mal ni te premien por el bien que dijeres della» (1991, I: 51). Desde esta premisa, no es de extrañar que el libro haya estimulado la imaginación lírica y haya alborotado la disciplina de las musas. La riqueza de las reflexiones vertidas en sus páginas $\mathrm{y}$, sobre todo, la universalidad de los personajes que la protagonizan explican el trasvase de la prosa al verso, ya que sus páginas permiten abarcar un amplio espectro de actitudes e inquietudes poéticas. No en vano, el poeta que versifica sobre los pasajes y personajes ideados por Cervantes 
pasa de ser lector del Quijote a convertirse en escritor subsidiario del Quijote, en una sugerente vuelta de tuerca al síndrome de Pierre Menard ( $c f$. Morón Olivares 2007: 165).

En la literatura española contemporánea conviven Alonso Quijano, el hidalgo que regresa al redil de la realidad cotidiana tras su paseo por la realidad virtual destilada en las novelas de caballería, y don Quijote, cuya locura se ha concebido a menudo como una forma superior de lucidez. En la lírica de comienzos del siglo XX, caracterizada por el repliegue meditativo, el simbolismo telúrico y el afán regeneracionista, cabría esperar que hubiese triunfado el juicioso Quijano sobre el disparatado Quijote. Sin embargo, la poesía hispánica no eligió al hidalgo cuerdo para troquelar sobre él su modelo cívico, sino que se inclinó por el héroe loco para promover una llamada a la acción sustentada en el idealismo. En contraste con la sensibilidad ilustrada, prevalecería el emblema romántico del caballero andante como encarnación de la libertad, incluso cuando sus aventuras se aplican al diagnóstico de los males de la patria o a la indagación en su etiología ${ }^{1}$. Baste recordar la prescripción quirúrgica de Ganivet a la altura de 1898: "Quiero decir con esto que don Quijote hizo tres salidas, y que España no ha hecho más que una y aún le faltan dos para sanar y morir» (García Sánchez 2005: 150). Al tiempo que el de la Triste Figura se eleva en paradigma de la solidaridad con los vencidos y de la dignidad de la derrota, sus peripecias funcionan como un «mitologema nacional» ( $c f$. Varela Olea 2003: 55-115) o como un espejo colectivo en el que se reflejan la identidad secreta de España y la psicología de sus habitantes, entre la mitificación de la patria y las miserias de la cruda realidad. Según afirma García Montero (2005: 14), «la España progresista, conmovida por sus fracasos, se olvidó de su propio proyecto y se identificó con la leyenda romántica del eterno derrotado», hasta el punto de que la intelectualidad noventayochista hubiese podido suscribir el primer verso del «Soneto en fuga a don Quijote», de Gerardo Diego: «Me erijo en don Quijote. Al fin existo» (García Jambrina 2005: 211).

Así las cosas, Rubén Darío rompió una lanza por el héroe melancólico y revolucionario («Letanía de Nuestro Señor don Quijote»), Miguel de Unamuno lo dotó de espesor existencial y entraña agónica («La última querella de don Quijote»), y Antonio Machado lo vio como un Mairena adelantado, cuya locura contenía una sabiduría proverbial y cuya nobleza espiritual trazaba un paralelismo en negativo con la pulsión fratricida de Caín («España, en paz»). Desde la diáspora se acuñaría la imagen de un caballero «en derrota, nunca en doma», por decirlo al modo de Claudio Rodríguez. León Felipe soñó con un mesías encadenado al Gólgota de una nación rota («El poeta prometeico»),

1. De hecho, la sublimación romántica de don Quijote, sancionada por la lectura de Schelling y los hermanos Schlegel, se fundamentaba en la contraposición entre el héroe y su escudero: mientras que el primero se identificaba con las aspiraciones elevadas, los valores espirituales o los matices de una «locura apolínea», el segundo era el exponente de los apetitos mundanos, los afanes materiales o las pulsiones dionisiacas ( $c f$. Close 2005: 19-20). 
y Pedro Garfías clamó en el desierto de su peregrinaje con la voz coral de todos los desheredados: «iQue viene Don Quijote y va hacia Dios!» ( $c f$. Díez de Revenga 2005: 723-726). Ya en el medio siglo, Blas de Otero se propuso sintetizar al personaje y a su demiurgo, mezclar historia e intrahistoria, y añadir una pizca de levadura intertextual a la harina épica ( $c f$. Alarcos Martínez 2007: 338-354): lejos de las adherencias previas, poemas como «Letra» $\mathrm{y}$ «La muerte de don Quijote» sirven de soporte a un Quijote reciclado en una suerte de icono antifranquista ${ }^{2}$. Este caballero andariego y politizado se erige en el complemento del Sancho Panza al que Gabriel Celaya había ensalzado en Cantos iberos (1955), en un intento de transformar al célebre escudero en metáfora expansiva del pueblo en marcha ${ }^{3}$.

Si en la poesía española al loco soñador le tocó la parte del león, la propina de la cordura no estuvo representada por Alonso Quijano, sino por Cervantes, según la interpretación defendida por José Ortega y Gasset (Meditaciones del Quijote, 1914), Américo Castro (El pensamiento de Cervantes, 1925) o Manuel Azaña (La invención del Quijote y otros ensayos, 1934). Así, Cervantes ilustra la capacidad de la invención literaria para fundir la conciencia individual y las experiencias colectivas. La impronta cervantina se aprecia en una pléyade de transterrados que no solo sienten nostalgia de su patria geográfica, sino también de una tierra literaria retratada «[s]egún la tradición generosa de Cervantes», como escribió Cernuda (1974: 482) en la segunda sección de su «Díptico español». En dicha vertiente se alinean asimismo otros nombres señeros de la Edad de Plata, como Jorge Guillén («Noche del caballero» y «Dimisión de Sancho») o Pedro Salinas («Verbo»). Por otra parte, desde la trinchera arraigada, Luis Felipe Vivanco compuso una conturbadora y polifónica «Elegía de Cervantes». Y la nómina de quijotextos poéticos podría extenderse a las aportaciones de Leopoldo de Luis, Gloria Fuertes, José Hierro o Jenaro Talens, entre muchos otros ( $c f$. Van-Halen 2005: 123-131) .

La oposición excluyente entre el de la Triste Figura y Cervantes - o, lo que es lo mismo, entre el personaje y su demiurgo- impide la sutura por la que había abogado Azorín (Con Cervantes, 1947), para quien era necesario compatibilizar a don Quijote y al Caballero del Verde Gabán hasta conseguir que los «espíritus solidarios, errabundos, fantásticos y perseguidores del ideal» dialogaran con aquellos otros «prosaicos, metódicos, respetuosos con

2. Como apunta Morón Olivares (2007: 174), es lógico que la España desarraigada prefiriera la ambigüedad simbólica de don Quijote a la rotundidad afirmativa del Cid, asimilado a la retórica y a la iconografía de los vencedores en la contienda civil.

3. En el contexto de la actual crisis económica, Antonio Orihuela (2016) se ha sumado a la interpretación del Quijote como una gran metáfora social que contrapone el afán justiciero de don Quijote a las falacias de los nuevos encantadores, «con sus medios de comunicación, con sus discursos mercenarios, con su lejanía de la realidad, con su orden institucional, con sus leyes mordaza, con sus fuerzas represivas, sus lacayos, sus siervos y sus bufones...».

4. El crítico y poeta ofrece una amplia enumeración que da cuenta de la recepción del Quijote en numerosos autores españoles e hispanoamericanos de los siglos XX y XXI. Con todo, la intención puramente informativa del artículo no permite extraer ninguna conclusión general más allá de corroborar la vigencia de la obra cervantina e invitar a la lectura de los poemas inspirados en ella. 
las tradiciones, amantes de las leyes, activos, laboriosos y honrados, mercaderes, industriales, artesanos y labradores» (García Sánchez 2005: 244). No obstante, la historia demostraría que en ninguna de las dos Españas existía un espacio donde pudieran coexistir las grandes empresas del arte y las pequeñas y medianas empresas de la vida diaria.

A diferencia de ese palpitante retablo quijotesco, las últimas promociones poéticas parecen haber orillado al ingenioso hidalgo, debido a su instrumentalización ideológica y a cierta calcificación en su simbología. De hecho, su vitalidad narrativa - Andrés Trapiello (Al morir don Quijote, 20045; El final de Sancho Panza y otras suertes, 2014); Marina Perezagua (Don Quijote en Manhattan, 2016) - y dramática -Els Joglars (En un lugar de Manhattan, 2005); Ron Lalá (En un lugar del Quijote, 2013) - contrasta con la escasa atención que la lírica reciente le ha dispensado. Sin embargo, a pesar de que su presencia cuantitativa ha disminuido, la imagen de don Quijote ha adquirido nuevos matices cualitativos. En este artículo me centraré en algunos textos que destacan el carácter poliédrico del personaje en la poesía española surgida bajo los auspicios del efecto dos mil, como «Don Quijote» (Las arenas de Libia, 1998), de Manuel Vilas; «Primera salida de don Quijote» (en la antología La poesía, señor hidalgo, 2005), de Felipe Benítez Reyes; «Morirse de cordura» (Compañera de celda, 2006), de Ana Merino; y «Las confesiones de don Quijote» (La intimidad de la serpiente, 2003), de Luis García Montero.

\section{LA FORJA DE UN REBELDE: DE DON QUIJOTE A SAN QUIJOTE}

Las composiciones anteriores remiten, explícita o implícitamente, al dechado del quijotismo lírico en el otro principio de siglo: la «Letanía de Nuestro Señor don Quijote» (Cantos de vida y esperanza, 1905) de Rubén Darío, bajo cuya advocación se sitúa el poema de Vilas, y cuya atracción magnética justifica su condición de intertexto latente en las demás piezas citadas. Aunque no es este el lugar para un comentario exhaustivo del manifiesto poético de Darío, baste con apuntar que su «Letanía...» contribuyó a difundir una visión netamente romántica de la obra cervantina en el orbe hispánico. Sus versos se solidarizan con un don Quijote evocado como presencia activa e invocado

5. Al igual que sucede en el Quijote, Trapiello no se abstiene de introducir en su narrativa versos de cuño propio. Por ejemplo, Al morir don Quijote ofrece dos muestras apócrifas atribuidas a Sansón Carrasco: el primer cuarteto de un soneto encomiástico que canta al nuevo orden impuesto por don Quijote («Muriose al fin quien puso con su espada / un orden nuevo de justicia y sueño [...]») (2004: 61), y un ingenioso epitafio que subraya la distancia entre la realidad y el deseo: «Quien puede, quiera. / Quien quiere, pueda» (2004: 88). Este dístico pasará a la antología La poesía, señor hidalgo con el título de «Epitafio al morir don Quijote, escrito por el bachiller Sansón Carrasco» (García Montero 2005: 235) 
como numen tutelar 6 . Estamos, pues, ante una exaltada plegaria y una oda admirativa donde el poeta enciende una vela a un Quijote redentorista y otra al personaje universal, a través de la superposición de dos campos semánticos: el de la religión y el de la caballería. Por un lado, de acuerdo con las fórmulas y cláusulas litánicas, Darío postula la asimilación entre Cristo y don Quijote. Si a aquel se le denomina «Rey de reyes» y «Señor de señores» en diversos pasajes de la Biblia (Deuteronomio 10, 17; Apocalipsis 19, 16; Salmos 136, 3), este recibe los sobrenombres sucesivos de «rey de los hidalgos», «señor de los tristes», «noble peregrino de los peregrinos», «caballero errante de los caballeros», «barón de varones» (en una paronomasia que ratifica su aristocracia espiritual) y «príncipe de fieros». De este modo, el mensaje evangélico de don Quijote garantiza su permanencia como paradigma supremo de la humanidad y como criatura investida de propiedades divinas, de nuevo mediante un paralelismo con Jesucristo. A este «caballero de Cristo» se dirige el escritor según el esquema iterativo de la letanía religiosa. Después de la salutación inicial, las fórmulas «pro nobis ora», «ruega por nosotros»y «jlíbranos, señor!», que alternan en la composición, implican una exhortación para que triunfe la empresa salvífica de un don Quijote ornado de cualidades míticas y místicas ${ }^{7}$ :

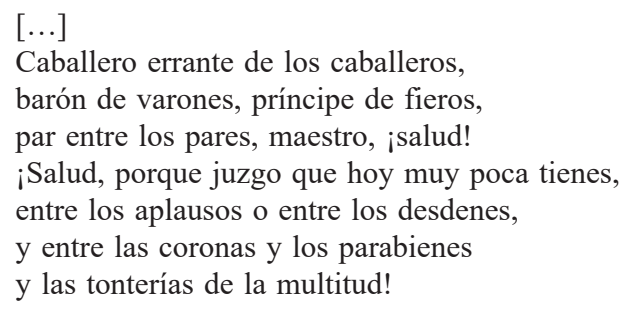

¡Tú, para quien pocas fueron las victorias antiguas, y para quien clásicas glorias serían apenas de ley y razón, soportas elogios, memorias, discursos, resistes certámenes, tarjetas, concursos, $y$, teniendo a Orfeo, tienes a orfeón!

Escucha, divino Rolando del sueño, a un enamorado de tu Clavileño, y cuyo Pegaso relincha hacia ti; escucha los versos de estas letanías, hechas con las cosas de todos los días y con otras que en lo misterioso vi.

6. En palabras del autor, «"Letanía de Nuestro Señor don Quijote” afirma otra vez mi arraigado idealismo, mi pasión por lo elevado y heroico» (Díez de Revenga 2005: 715-716).

7. En su análisis de la composición, Emilio Carilla (1951: 61-70) señalaba que el texto de Darío revela que el Quijote parece plegarse con mayor facilidad a la forma libre del desarrollo poemático que a la horma académica del estudio crítico. 


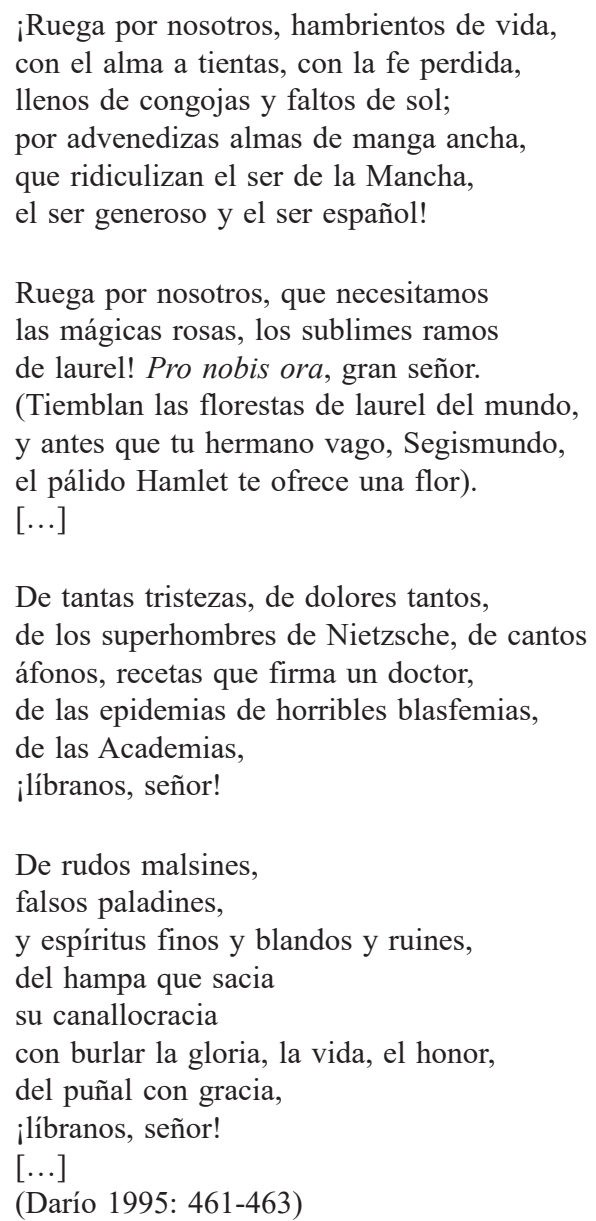

Darío reivindica aquí un ideal caballeresco llamado a restaurar la fantasía en medio de una realidad prosaica, en la que don Quijote ha sido secuestrado por sus exégetas y condenado a sufrir «los parabienes / y las tonterías de la multitud». El autor insta al personaje de Cervantes a que se subleve contra el coro de sus aduladores — «teniendo a Orfeo, tienes a orfeón»—, alivie los síntomas del mal du siècle - «[d]e tantas tristezas, de dolores tantos, / de los superhombres de Nietzsche»— y combata a los nuevos enemigos de la imaginación: «rudos malsines», «falsos paladines», «espíritus finos y blandos y ruines» y demás exponentes de la «canallocracia» burocrática. En esta nueva cruzada, la rebeldía de don Quijote se compara con la de los grandes soñadores de la literatura épico-dramática: el «divino Rolando», Segismundo o «el pálido Hamlet». Las dos estrofas finales, que repiten las del comienzo en un orden inverso, rubrican la mnemotecnia de la letanía, cierran la pieza con un broche circular y consagran a don Quijote como un arquetipo espiritual a partir del que podría canalizarse una admonición social. Todo ello hace del poema de Darío 
no solo una profesión de fe en el quijotismo o un compendio de doctrina moral, sino el «testimonio hispánico más representativo de la corriente finisecular de sacralización de la figura de don Quijote» (Palomo Alepuz 2016: 82).

\section{CENSURA DE LA LOCURA: DON QUIJOTE A TRAVÉS DEL ESPEJO}

Frente a la epifanía quijotesca de Darío, buena parte de la poesía actual se aproxima a don Quijote para poner de relieve el engaño de sus hazañas, el desatino de sus empresas y la distorsión de su identidad. El preciso diagnóstico de don Lorenzo de Miranda, hijo del Caballero del Verde Gabán — «él es un entreverado loco, lleno de lúcidos intervalos» (1991, II.18: 173)—, se impone así a la cautelosa impresión de su padre, don Diego de Miranda: «solo te sabré decir que le he visto hacer cosas del mayor loco del mundo, y decir razones tan discretas, que borran y deshacen sus hechos» (II.18: 170). Desde una óptica irónica, los poemas de Manuel Vilas y de Felipe Benítez Reyes proceden a una desmitificación burlesca del personaje, aunque sus planteamientos divergen en un aspecto: mientras que para el primero don Quijote aún mantiene una conexión simbólica con el tema de España, para el segundo no es más que un muñeco tragicómico en manos del destino.

En el díptico titulado «Don Quijote», Manuel Vilas promueve una doble interacción con el universo literario de Cervantes: en tanto que la primera parte ofrece un retrato caricaturesco del escritor y de su creación ficcional, fundidos en una sola entidad psíquica, la segunda profundiza en la relación cordial entre la novela y el poeta contemporáneo, desdoblado en el «desocupado lector» al que se refería el prólogo de la obra cervantina. A pesar de su contigüidad temática y retórica, cada una de las partes presenta cierta autonomía, lo que legitima que las leamos como secuencias aisladas, aunque surgidas de un mismo impulso creativo. La primera sección es sin duda la más interesante. En ella Vilas no se desliga de la interpretación simbólica que asocia a don Quijote con la marca España, pero invierte el legado regeneracionista y el corolario moral al que conducía dicha identificación. Ni Cervantes es aquí el genio menospreciado por sus paisanos, ni don Quijote el heraldo venido a instaurar un orden nuevo. Al contrario, ambos se consideran especímenes de un pandemonio hispánico - más cercano a la picaresca que a la épica - que condena al fracaso a quienes ansían la «gloria humana» o se dejan cegar por los espejismos de la celebridad. Si Cervantes ejemplifica ahora la sórdida paradoja de que «sea un menesteroso el hacedor de la inmortal fábula», don Quijote encarna el falso prestigio de la locura en un mundo de $\operatorname{locos}^{8}$. A pesar del epígrafe de Rubén Darío que precede a la composición, 
los versos de Vilas suponen un ataque sin cuartel contra las dos máscaras (la de la locura y la de la razón) que cubren alternativamente el rostro jánico de la nación:

DON QUIJOTE, I

Señor de los tristes...

R. D.

Ese hombre que no fue un sueño sino larga pesadilla, aliada de ridículo, deformidad, risa bárbara y lenta, metáfora de España, y aquel otro que la trajo del que tantas necedades dijeron falangistas en Academia, confusión con un dios ibero, ideal de una Hispania fecunda.

No gusta cómo España alaba a sus muertos, sea el uno o sea el otro, un sermón confuso, mohín del tiempo hipócrita; que sea un menesteroso el hacedor de la inmortal fábula; solo la muerte y los muchos siglos y el olvido de vida y la mentira dan el museo de una historia repelente, todo un pueblo a dos desconocidos reverenciando.

Y esos dos hombres, a cuál más pobre, a cuál más lelo: el loco redimido de su gris naturaleza entre el populacho que le ríe, el cuerdo que lo crea harto de la mitología y deseoso de vulgar solaz hallar entre las páginas inútiles.

El loco antiguo, hambriento y cómico, serrín en la mollera, un cincuentón célibe, honrado, indeseable, avariento de gloria humana cuando esta es una criatura torpe y culpable. $\mathrm{Su}$ fealdad me asusta, su pensamiento me corrompe, su profundidad no la siento, y su comedia me fatiga.

El uno sin mano y en la cárcel, el otro por el desierto de la Mancha sin seso y sin vergüenza.

Los dos ahítos de hambre, pobres, huraños de grandeza en su hispánica celebridad de pícaros, locos, ateos y santos. (Vilas 1998: 67)

Al margen de su visceralidad torrencial, a la que coadyuvan la disposición versicular y el tono de salmodia, esta pieza se construye como un elaborado tapiz intertextual en el que se dan cita Antonio Machado («El Dios ibero», de Campos de Castilla), Rubén Darío (la «Sangre de Hispania fecunda», extraída de «Salutación del optimista») y, sobre todo, Valle-Inclán. En efecto, no

en prosa de «Avenida de Madrid», un corpus incorporado a su Poesía completa: «Dedico este poema a Miguel de Cervantes, que se murió sin saberse Cervantes. Y a Rocinante, que cabalgó con la locura encima» (2016: 170-171). 
solo la «risa bárbara» del segundo verso podría hacer alusión a las Comedias bárbaras del autor gallego, sino que todo el poema entronca con la vitriólica deformación del esperpento, según la definición de Max Estrella en Luces de bohemia: «Los héroes clásicos reflejados en los espejos cóncavos dan el Esperpento. El sentido trágico de la vida española solo puede darse con una estética sistemáticamente deformada» (1985: 131-132). La imprecación de Vilas a la criatura cervantina y a su demiurgo compara las andanzas de ambos personajes mediante fórmulas distributivas que inciden en el paralelismo de sus respectivas trayectorias vitales, poco importa si reales o ficcionales: «[e]se hombre» / «aquel otro», «sea el uno / o sea el otro», «el loco redimido» / «el cuerdo que lo crea», «[e]l uno sin mano y en la cárcel, el otro por el desierto». La transfusión psíquica entre Cervantes y su invención literaria explica que Vilas acuse a don Quijote de tener "serrín en la mollera», una expresión que recuerda a la que había utilizado Cervantes al referirse a Sancho Panza: «hombre de bien — si es que este título se puede dar al que es pobre-, pero de muy poca sal en la mollera» (1991, I.7: 125). En suma, Vilas difumina aquí las fronteras entre locura y cordura para resaltar la soberanía de la miseria y la vana persecución de la fama como singularidades del alma española. Así, el término hambre del penúltimo verso se entiende tanto en sentido literal —recuérdese la orfandad gástrica de Lázaro de Tormes en el Lazarillo - como en sentido metafórico, en la medida en que remitiría al insaciable apetito de gloria de los dos personajes que protagonizan el poema: «Los dos ahítos de hambre, pobres, huraños de grandeza / en su hispánica celebridad de pícaros, locos, ateos y santosı ${ }^{9}$.

Por su parte, la segunda composición del díptico mitiga el juicio negativo del autor sobre la obra, al destacar la complicidad entre el Quijote y sus lectores: «Quiero yo pasar años enteros en estas páginas pacíficas, / entretenido vanamente con los acontecimientos que Cervantes inventara» (Vilas 1998: 68). En consecuencia, también cambia la actitud hacia Cervantes, de quien se ponderan su tolerancia y su generosidad, a pesar de la aspereza de sus avatares biográficos: «Esa indulgencia del escritor hacia la vida cuando esta no le fue indulgente / es también misterio de la Edad de Oro, una secreta venganza, / un don de los dioses a la inteligencia ocupada en la ganancia del sustento» (1998: 68 $)^{10}$. Finalmente, Vilas insiste en la lectura de la obra como una alegoría encriptada de la esencia de España, gracias al papel que desempeña «un

9. Algo similar se afirma, con cáustica ironía, en «Spanish dream» (El hundimiento, 2015), aunque ahora quien padece las estrecheces de la patria no es Cervantes, sino el propio sujeto poético: «España, nos das trabajos muy dolorosos. / España, no tengo un duro y mis libros se venden poco y no / puedo vivir de mi trabajo, y trabajo para nadie. / Solo sé escribir y me estoy quedando sin palabras» (Vilas 2016: 628).

10. Ya en el texto en prosa «El Quijote hoy en la cultura española», que recoge la participación del autor en los encuentros de Verines celebrados en 2005, Vilas desarrollaba esa misma idea: «El Quijote es un libro maravillosamente indulgente para con la vida. Es un libro sin queja, un libro sin queja escrito por un hombre que sufrió y padeció persecución e injusticia a lo largo de su vida. Esto también es un misterio muy cervantino, un misterio de alquimia moral: cómo desde una vida castigada se puede construir un libro absolutamente enamorado de la vida» (2005: 3). 
hombre atacado de rancia retórica cuyos cambiantes juicios / vinieron a este mundo para traernos el culo retozón de mozas rudas, / el color de los caminos, la acémila ridícula, un vulgo ferviente, / la esencia de España que fue siempre / la conversación inacabable entre dos del mismo pueblo» (1998: 68). A la vez guía de peregrinos y mapa de carreteras, para Vilas el Quijote avanza el estereotipo de la España negra, prefigura los garrotazos visuales de Goya y conjura los demonios de un "país de todos los demonios», como escribió Gil de Biedma ${ }^{11}$.

La prosaica existencia que Vilas atribuye a Cervantes y a don Quijote converge en el perfil individual del trastornado hidalgo en «Primera salida de don Quijote», de Felipe Benítez Reyes, incluido en la antología La poesía, señor hidalgo. Como se ha dicho, la dimensión simbólica desaparece por completo en un poema que aboga por una recuperación de la vertiente jocosa del Quijote, más allá de los valores metafóricos que se le han ido superponiendo a lo largo y ancho de la tradición literaria. Ya en su artículo «La crueldad aplicada a unos muñecos», Benítez Reyes (1999: 25) manifestaba su extrañeza ante «las lecturas que inciden en la ejemplaridad idealista del Quijote [...], especialmente si nos paramos a pensar durante un par de minutos en la curiosa extravagancia que supone el hecho de aceptar como arquetipo de la razón y del idealismo a un loco iracundo». Según Benítez Reyes, la consideración de don Quijote como un «patético pelele» destinado a provocar la burla de los lectores corregiría una desviación interpretativa perpetuada por la ecdótica cervantina. La complejidad del Quijote residiría, en esencia, en un problema más humano que artístico, directamente relacionado con la conflictiva psicología de quien protagoniza el relato: «El Quijote tal vez no sea tanto una novela estructurada en torno a la locura de un personaje como una novela protagonizada por un chiflado» (1999: 25). Esta recalificación humorística del Quijote no es incompatible, sin embargo, con la fascinación estética que desprende la obra de Cervantes, ni con la compasión cordial que despierta su caballero. Da igual si la conmiseración hacia el de la Triste Figura obedece a un plan preestablecido o es un efecto colateral de sus accidentadas aventuras: lo sustantivo es su indiscutible eficacia narrativa. Para Benítez Reyes (1999: 30), la adhesión que genera don Quijote no se debe a «ningún tipo de sentimiento especialmente elevado», sino a un puro «instinto compasivo».

Ese instinto compasivo se encuentra filtrado por el tamiz de la razón en «Primera salida de don Quijote». En este soneto asonantado, Benítez Reyes nos muestra a don Quijote a punto de entrar en acción («en un rocín al trote, va el caballero triste»), según la descripción que realiza Cervantes en el capítulo segundo de la primera parte de su novela: «El famoso caballero don Quijote de la Mancha [...] subió sobre su famoso caballo Rocinante, y comenzó a caminar por el antiguo y conocido campo de Montiel» (1991, I.2:

11. La reactivación crítica del estereotipo de la España desértica y mesetaria puede verse en el reciente ensayo La España vacía. Viaje por un país que nunca fue (2016), de Sergio del Molino. 
80). Aunque don Quijote ocupa el centro de la composición, el poeta guarda en todo momento las distancias con el personaje. Al igual que Vilas, Benítez Reyes opta por la tercera persona para esbozar su peculiar retrato robot del héroe. Sin embargo, frente a la deformación esperpéntica de aquel, la desmitificación de don Quijote es aquí el resultado de un análisis que oscila entre la observación notarial y el estudio de un trastorno clínico. Con todo, la emoción en sordina de los tercetos permite adivinar una cierta empatía hacia el caballero:

\section{PRIMERA SALIDA DE DON QUIJOTE}

Lunático en su luna, vagamundo hechizado, absorto en sus quimeras de endriagos y amadises, su estampa reflejada, ojival, en los charcos, en un rocín al trote, va el caballero triste.

Quijote en su impostura, Quijano alucinado, mohosa la armadura, indigno el morrión simple, anda en busca de lances de corte sobrehumano: leones y molinos, gigantes y merlines.

Qué frágil caballero, ¿verdad?, con su vesania nacida del veneno verbal de las ficciones, perdido en sus delirios de magia y de poder.

Qué destino tan alto y qué suerte tan mala. Qué ilustre marioneta de los encantadores, lanzado a los peligros del campo de Montiel.

(Benítez Reyes, en García Montero 2005: 245)

El ensimismamiento de don Quijote se expone con claridad desde el verso inicial, en el que irrumpe como un sujeto alienado y expulsado de la realidad: un «lunático en su luna»y un «vagamundo hechizado», jugando con las acepciones de lunático (persona que padece episodios de locura o persona cuyos cambios de humor están influidos por las fases de la luna) y de hechizado (sometido a encantamientos maléficos o alelado, ofuscado, según el célebre apodo que recibió Carlos II). Los cuartetos entregan una prosopografía del caballero, especulan sobre la causa de su enajenación, refieren su desdoblamiento a partir de la identidad matriz de Alonso Quijano, glosan su precario bagaje caballeresco y enumeran algunas de sus proezas más conocidas, como sus batallas contra «leones y molinos, gigantes y merlines». A su vez, los tercetos funcionan como una reflexión en voz alta o un diálogo con los lectores, a los que se interpela mediante la interrogación retórica: «¿verdad?». El retrato proyectivo del héroe se sustituye entonces por la evaluación retrospectiva de sus hazañas, sostenida en la repetición anafórica del «qué» admirativo. Más allá de la irónica refutación del «veneno verbal de las ficcio- 
nes», el poema trasluce el asombro ante los paradójicos lances de la fortuna y el contraste entre el empeño del héroe y los imperativos de la realidad ${ }^{12}$. Al cabo, el voluntarioso caballero acabará exhibiendo su condición de juguete roto o muñeco trágico en manos del azar: «Qué ilustre marioneta de los encantadores / lanzado a los peligros del campo de Montiel». La discordancia semántica entre los encantadores y las tierras de Montiel traduce la escisión entre Quijote y Quijano; entre la percepción del personaje ficticio y el campo literario donde se lleva a cabo la representación ${ }^{13}$. La personalidad quimérica de don Quijote se reitera gracias a determinadas expresiones que inciden en el léxico de la locura («absorto», «alucinado», «perdido en sus delirios», «con su vesania»), y se intensifica con ciertas referencias a su personalidad quebradiza, ya sea a través de una prosaica proyección especular (el reflejo de su estampa en los charcos) o de la mención a su fragilidad («[q]ué frágil caballero»). Al tiempo cruel y compasiva, la pieza de Benítez Reyes subraya los paralelismos entre don Quijote y su hermanastro Tomás Rodaja, abismado en su fantasía de espejos cóncavos ${ }^{14}$.

Protagonizados por la maleable figura de don Quijote, los textos de Vilas y de Benítez Reyes desmontan dos rasgos inherentes al personaje, tal como lo había retratado la tradición lírica del siglo XX. Por un lado, el contorno mítico y el perfil heroico de don Quijote se reemplazan por el reverso desmitificado y la desfiguración antiheroica. En este sentido, don Quijote pierde su intermitente lucidez para asimilarse a la imagen de un loco asediado por sus alucinaciones, a ratos cómico y a ratos trágico. Por otro lado, el idealismo quijotesco se sustituye por una visión vulgar de sus hazañas, ya sea mediante una distorsión esperpéntica, degradante y feísta (en el caso de Vilas), o mediante una lectura realista, prosaica y compasiva (en el de Benítez Reyes). Por último, si Vilas aún forzaba el paralelismo simbólico entre don Quijote y la idiosincrasia de España, Benítez Reyes emancipa al personaje de toda servidumbre cívica, social o histórica, y lo devuelve al territorio de la pura ficción novelesca. Después de su recorrido por la poesía de finales del siglo XX y comienzos del XXI, don Quijote se parece más al maltrecho títere de don Gaiferos en el retablo de maese Pedro que al invicto soñador que había postulado Rubén Darío, volando hacia la libertad a lomos de Clavileño.

12. Ya en su discurso «Psicología de don Quijote y el quijotismo», leído en el Colegio Médico de San Carlos el 9 de mayo de 1905, Ramón y Cajal había advertido que las malandanzas que tuercen el «alto destino» del caballero chocan con su enérgica y desbordante «fe ciega en la fortuna, fe característica de los grandes conquistadores de almas y de tierras» (García Sánchez 2005: 30).

13. Esa dramatización entronca con el «Don Quijote» (Teatro real, 1957) de Leopoldo de Luis, en el que este se erigía también en un personaje en busca de autor, extraviado en el gran teatro del mundo (cf. Morón Olivares 2007: 173-174).

14. Véase el famoso dictamen de Cervantes sobre la peculiar enajenación del licenciado Vidriera: «[...] quedó sano, y loco de la más extraña locura que entre las locuras hasta entonces se había visto. Imaginose el desdichado que era todo hecho de vidrio, y con esta imaginación, cuando alguno se llegaba a él, daba terribles voces pidiendo y suplicando con palabras y razones concertadas que no se le acercasen, porque le quebrarían; que real y verdaderamente él no era como los otros hombres: que todo era de vidrio de pies a cabeza» (1994: 656). 


\title{
ELOGIO DE LA CORDURA: PALABRA DE QUIJANO
}

La impugnación de la locura en los poemas anteriores convive con la exaltación de la lucidez por la que apuestan otras composiciones. No obstante, a diferencia de lo que había ocurrido en la poesía española de las décadas anteriores, no le corresponde ahora a Cervantes — paradigma de la conciencia autorial - la misión de arrimar el ascua de la razón a las páginas de la novela. La alabanza de la cordura no exige saltar las bardas de la obra literaria ni acudir al socorro del paratexto, sino que puede escenificarse dentro de la propia narración y ejemplificarse por medio de los personajes que aparecen en ella.

Prueba de este desplazamiento es «Morirse de cordura», de Ana Merino. La dedicatoria «a Alonso Quijano el Bueno» no deja lugar a dudas sobre el destinatario de los versos ni sobre el episodio al que remite, pues se le transfiere al héroe el sobrenombre con el que él mismo se designa al recobrar la cordura, en el desenlace de la novela: «Dadme albricias, buenos señores, de que ya yo no soy don Quijote de la Mancha, sino Alonso Quijano, a quien mis costumbres me dieron renombre de Bueno» (1991, II.74: 588). Por tanto, la voz lírica se dirige en segunda persona a Alonso Quijano para recordarle el origen libresco de sus desvaríos y la fantasmagoría de sus peripecias caballerescas:

\author{
Ya tienes juicio, \\ se agota tu ser \\ desencantado \\ de saberse mortal, \\ frágil y cuerdo. \\ Todo lo que creías \\ era solo extrañeza \\ de sombras familiares \\ transformada en invento. \\ Los libros fabricaban \\ el aliento inmortal \\ de los que habitan \\ en los encantamientos. \\ Y tú eras invencible \\ imaginando anhelos \\ en las palabras nuevas \\ de los miedos ajenos. \\ (Merino 2006: 27)
}

No obstante, la presencia de un yo en la última estrofa da un giro imprevisto a la composición: lo que hasta entonces habíamos interpretado como una 
amonestación de la poeta actual al inmortal personaje literario se revela como un artificio retórico. En realidad, la voz enunciativa que escuchamos aquí se identifica con la de Aldonza Lorenzo / Dulcinea, que lamenta la recuperación de la cordura por parte de don Quijote:
Ahora que la cordura
es tu epitafio
ya no podrá existir
lo que soñabas,
ya no podré vivir
en tu locura,
vestida de espejismo
cosido a tu mirada.
(Merino 2006: 27-28)

El desencanto de Alonso Quijano implica el definitivo desencantamiento de Dulcinea del Toboso. Al desvanecerse la fantasía sobre la que don Quijote había cimentado su arquitectura narrativa, Dulcinea también debe renunciar al estatuto de dama, princesa y gran señora que le había otorgado el hidalgo en sus alucinaciones: «Llamábase Aldonza Lorenzo, y a esta le pareció ser bien darle título de señora de sus pensamientos, y buscándole nombre que no desdijese mucho del suyo y que tirase y se encaminase al de princesa y gran señora, vino a llamarla Dulcinea del Toboso, porque era natural del Toboso» (1991, I.1: 78) ${ }^{15}$. En el poema de Ana Merino, el desengaño de Alonso Quijano es simultáneo al de su objeto de deseo: al igual que le ocurre a este con respecto a su álter ego heroico, Aldonza Lorenzo se ve obligada a cancelar su identidad virtual (dama caballeresca) para conformarse con su identidad real (campesina manchega). Puesta al descubierto la impostura novelesca, la protagonista del texto ha de resignarse a la existencia común de la que la había redimido el amor platónico del falso caballero. Los versos finales suscriben el título de la composición: a causa de su dependencia recíproca, tanto don Quijote como Dulcinea mueren en el preciso instante en el que Alonso Quijano reconquista su nombre y su apellido, abraza la cordura y exhala su último aliento. La simpar Dulcinea, que solo existe en la perturbada imaginación del héroe, sucumbe cuando se apaga la ficción de quien la inventa. Como indica al respecto Almudena Grandes (1999: 108), Dulcinea no solo define al caballero y justifica sus aventuras, sino que «se convierte en un espejo exactísimo de la imprevisible

15. Esta idealización se parodia en el episodio en el que Sansón Carrasco, disfrazado de Caballero de los Espejos, emplea la misma retórica caballeresca y los mismos usos toponímicos que don Quijote para ponderar el linaje de su supuesta dama: el «Caballero de la Triste Figura [...] tiene por señora de su voluntad a una tal Dulcinea del Toboso, llamada a un tiempo Aldonza Lorenzo; como la mía, que, por llamarse Casilda y ser de la Andalucía, yo la llamo Casildea de Vandalia» (1991, II.14: 136). 
combinación de existencia e inexistencia que constituye la naturaleza de nuestro personaje» ${ }^{16}$.

Ana Merino le pasa el micrófono a una Dulcinea literal y metafóricamente desencantada para prevenirnos de los riesgos de la excesiva cordura y construir un trampantojo metapoético. Gracias a esta operación, la autora consigue dotar al discurso de una pudorosa trama sentimental, lejos de la estridente proclamación amorosa de don Quijote, y dar voz a un personaje silenciado en la novela, hasta el punto de ser más un nombre que una entidad de carne y tinta ${ }^{17}$. Aunque la breve intervención de Dulcinea no permite hablar en sentido estricto de un monólogo dramático — pues no se produce la suspensión del juicio moral que Langbaum (1996: 125) requería de este resorte- Ana Merino propone una nueva mirada al Quijote desde una óptica femenina y desde un enfoque confesional, en los antípodas del chafarrinón expresivo de Vilas y de la frialdad expositiva de Benítez Reyes.

El soporte autorreflexivo de «Morirse de cordura» se despliega en el poema más representativo del quijotismo a comienzos del siglo XXI: «Las confesiones de don Quijote», de Luis García Montero. Pese a su cariz metapoético, estas «confesiones» se distancian del pastiche revisionista - manierista y posmoderno a la vez - que hallamos en las composiciones urbanas de $R i$ mado de ciudad (1983). Al mismo tiempo, el paseo por el territorio de la ficción aleja a esta pieza de algunas obras de correlato histórico, como los monólogos dramáticos «Larra» (Las flores del frío, 1991) y «El insomnio de Jovellanos» (Habitaciones separadas, 1994). El propio título de «Las confesiones de don Quijote» resulta ambiguo, pues estas no son unas confesiones al uso. La plantilla autobiográfica y la justificación retrospectiva inherentes al género se sustituyen por la modulación de una confidencia cómplice, según la preferencia del autor que le insufla nueva vida a la invención cervantina: «El tono de poesía que más me interesa [es] el que se elabora en el truco de la sencilla confesión amistosa, a través del artificio estético de la naturalidad» (García Montero 2006: 553) ${ }^{18}$. Si el término confesiones es conflictivo, el otro elemento del título tampoco está exento de problemas. De hecho, don Quijote es aquí un personaje ausente, cuyas aparatosas gestas funcionan como referente implícito, resonancia inconsciente y eco intertextual. Desde el princi-

16. En el poema de Ana Merino se desarrolla un proceso contrario al de la «Dulcinea» de Villaespesa, que apelaba a la capacidad de metamorfosis del arte para transformar la tosca carnalidad de una Dulcinea tabernaria en una belleza sobria y honesta. Otras proyecciones líricas de Dulcinea la conciben como modelo abstracto de una realidad concreta, determinada por el paisaje («La mujer manchega», de Antonio Machado), o la trasponen a un espacio geográfico que le resulta ajeno (la Dulcinea mestiza que aparece en «Don Quijote trasterrado», de José Hierro).

17. No en vano, Ana Merino ha editado, junto con Raquel Lanseros, la antología Poesía soy yo (2016), cuyo objetivo es recuperar las voces de poetas españolas e hispanoamericanas del siglo XX que, a juicio de las antólogas, habrían sido postergadas en el canon por su condición femenina.

18. Esta acepción de confesión se separa tanto del anecdotario individual como de la ética testimonial. En cambio, García Montero vincula el término con el registro meditativo que defienden los escritos reunidos en el volumen Confesiones poéticas (1993), o el poema «Confesiones» (Completamente viernes, 1998). 
pio, García Montero opta por la persona prosaica que se embosca tras la capa y la espada del superhéroe caballeresco: «Casi nadie me llama por mi nombre, / vulgar y cotidiano como la rebeldía». Estos versos despejan la incógnita sobre la identidad del hablante y nos avisan de que el protagonista de la confesión va a ser el hidalgo manchego, «no la triste figura del loco romántico» (García 2007: 59). La elección de Alonso Quijano, en detrimento de don Quijote, aporta ya numerosas pistas sobre el posterior desarrollo de la composición. Si durante buena parte del siglo XX Alonso Quijano había sido el símbolo del retraimiento en la subjetividad íntima, o incluso de la reclusión en la política interna - ejemplo de quien abandona «las aventuras extranjeras para dedicar[se] a labrar la hacienda propia» (Varela Olea 2003: 14) —, ahora la apuesta de García Montero consiste precisamente en reivindicar la rebeldía cotidiana del hidalgo; una rebeldía que «no es patrimonio de los héroes sino conquista de la gente común» (Morón Olivares 2007: 179) ${ }^{19}$.

En las primeras estrofas (de la 1 a la 5), Alonso Quijano rememora las aventuras vividas bajo el sobrenombre de don Quijote, evoca algunos de los pasajes más famosos de la novela y denuncia la crueldad de las normas cortesanas a partir de la conducta de los duques en la segunda parte de la obra. Sin embargo, aún predomina la isotopía de la locura o de la alucinación, tal como se aprecia en los sintagmas «la nobleza ridícula que yo mismo elegí», «una triste ilusión», «el delirio de mis noches», «la cabalgadura de los sueños», «un reino de fantasmas» o «el jardín de un manicomio»:

Casi nadie me llama por mi nombre, vulgar y cotidiano como la rebeldía.

\author{
Prefieren otorgarme \\ la nobleza ridícula que yo mismo elegí, \\ el título de un pobre caballero, \\ de una triste ilusión, \\ y me recuerdan hoy \\ por el delirio de mis noches, \\ alunado, valiente \\ en la cabalgadura de los sueños \\ al confundir gigantes y molinos. \\ No les resulta fácil \\ convivir con el nombre de las cosas. \\ El dolor y el desvelo \\ convierten los rebaños en batallas, \\ las cuevas en enigmas \\ y la fealdad inhóspita en belleza.
}

19. Según ha sentenciado el autor, con un flash aforístico, «[d]efender la razón ilustrada en medio de la cultura occidental es hoy una manía lunática» (García Montero 2008: 12). 
Hermosa y respetable es la locura, como la débil caridad del sueño, hasta que descubrimos las razones del Duque, que invita al soñador y hace volar al loco para fundar las normas de su corte, las risas y los pleitos que pudren corazones cortesanos.

Y ya no somos sombras, sino cuerpos sin sombras, ojos sin nadie que viven en un reino de fantasmas y han borrado las huellas de sus nombres con un guante de plástico, prendidos al vacío, entre rosales pulcros y espinas bien cortadas, como el jardín de un manicomio.

Madreselvas y lilas alrededor de las preguntas y de las soleadas canciones de los médicos. (García Montero 2006: 542-543)

La sexta estrofa incluye una declaración de principios («Soy Alonso Quijano. / Yo recordé mi nombre en Barcelona») que desvela el formato confesional y entronca con la anagnórisis final del Quijote, a la que ya hemos aludido al comentar el poema de Ana Merino. El fracaso del avatar caballeresco despierta la autoconciencia del enunciador. Así se observa en el rotundo epifonema «[f]ui derribado por mi propia burla», que abre la séptima estrofa y prefigura la derrota de don Quijote a manos del Caballero de la Blanca Luna: «Los duelos perdidos / con los representantes de la luna».

Hasta aquí llega lo que cabalmente podría calificarse como confesión. No obstante, el truncamiento de las expectativas se materializa en la octava estrofa, en la que se incorporan nuevas formas pronominales y nuevos espacios discursivos. En este momento, Alonso Quijano / don Quijote se libera de su condición de criatura novelesca y va al encuentro de un escritor enmarcado en un cronotopo específico: alguien que se aloja en una habitación de hotel en Barcelona, en la noche del 23 de junio. La visita de la entidad ficcional al autor real nos retrotrae a una estrategia empleada desde Niebla de Unamuno hasta El Levante de Cartarescu, por no mencionar los cameos de Cide Hamete en la trama y en la tramoya quijotescas:

Esta tarde de junio y de San Juan, en esta solitaria habitación de hotel que nos buscó el azar de la poesía, regreso a Barcelona a importunarte con mis confesiones, porque sigues ahí, 
en el lugar de la ficción,

suspenso una vez más

delante del papel,

con el bolígrafo apuntando al cielo,

la mano en la mejilla

y el codo en el bufete.

(García Montero 2006: 544)

Cabría preguntarse quién es el interlocutor de Quijano / Quijote, ese tú «suspenso una vez más, / delante del papel». La imagen remite a la semblanza que Cervantes ofrece de sí mismo en el prólogo de su obra: «Muchas veces tomé la pluma para escribille, y muchas la dejé, por no saber lo que escribiría; y estando una suspenso, con el papel delante, la pluma en la oreja, el codo en el bufete y la mano en la mejilla [...]» (1991: 51-52). Sin embargo, la actualización de escenografía y atrezo - la habitación de hotel en vez del despacho y el bolígrafo en vez la pluma - apunta a otra posibilidad no menos atractiva: el escritor bloqueado al que importuna el personaje bien podría ser un desdoblamiento del propio Luis García Montero. Esta hipótesis resalta el juego de la figuración estética (García Montero 1996: 75; Scarano 2004: 37). El poeta nos invita a asumir la dimensión convencional de la literatura - entre el artificio de las reglas y el placer de romper con ellas- para instaurar un nuevo «pacto realista» (Juaristi 1994: 25-26) o para sumergirnos en un «pacto de verosimilitud que trabaja también con el realismo inverosímil» (García Montero 1999: 87). Incluso cabe aventurar una analogía entre la descripción que contienen estos versos y el célebre retrato de Jovellanos pintado por Goya. No en vano, el codo en el escritorio y la mano en la mejilla pertenecen a la iconografía con la que se asocia el pensador ilustrado. Esta equiparación no resulta gratuita, ya que la voz poética parece dialogar con la del Jovellanos exiliado en el castillo de Bellver que había protagonizado «El insomnio de Jovellanos». Si allí el mar era un símbolo de las fluctuaciones dinámicas de la historia, con sus avances y retrocesos, en estas «confesiones» se convierte en la frontera artificial que nos invita a distinguir la orilla de la realidad y la altamar de la ficción, el vibrante caleidoscopio urbano y el ámbito de la introspección creativa ${ }^{20}$.

Las siguientes estrofas (de la 9 a la 12) sitúan el coloquio de los protagonistas en un entorno urbano de tintes experienciales: «Abre el balcón / y asómate a las Ramblas». El gesto de apertura al exterior supone mezclar las convicciones

20. El monólogo de Jovellanos y el de Alonso Quijano coinciden en su voluntad de conectar los espejismos del sueño con el descrédito de las utopías ( $c f$. Andújar Almansa 2011: 214-215). Si Jovellanos había certificado la ruina de las expectativas reformistas — «Porque sé que los sueños se corrompen, / he dejado los sueños» (García Montero 2006: 344)_, Quijano suscribe la fractura de las ilusiones individuales: «Porque resulta hermosa y respetable / la caridad del sueño, / se han celebrado mucho mis hazañas». Junto con el intertexto de Habitaciones separadas, Morón Olivares (2007: 179) aprecia la influencia de otro monólogo: el «Soliloquio del farero» (Invocaciones, 1934-1935), de Luis Cernuda, con el que el poema actual podría relacionarse a través de su iconografía marítima, su alerta ética y su «verdad solitaria». 
privadas con las ambiciones públicas, el papel del ciudadano con la labor del político. Conforme avanza el discurso, el ángulo del paisaje va ampliándose hasta acoger al paisanaje del siglo XXI y transcribir su clima moral. En esa intemperie cívica se dan cita hombres y mujeres aquejados de prisa, caballos que miden la potencia de los vehículos y leyes que se erigen en las nuevas novelas de caballería en las que creer ciegamente, una vez que los metarrelatos del capital se han reemplazado por las pequeñas narraciones del neoliberalismo:

Porque resulta hermosa y respetable

la caridad del sueño,

se han celebrado mucho mis hazañas.

Pero si quieres verme,

más allá de los himnos de mi triste figura,

y saber cómo fui

en el paisaje oscuro de mi tiempo,

o cómo soy ahora

entre las libertades de tu siglo,

abre el balcón

y asómate a las Ramblas.

Pasa la multitud, cumple la historia de sus mercados y sus oficinas.

Hay hombres y mujeres

que cambian de argumento al detener un taxi, besos que solo son una frontera

para volver a un domicilio,

colecciones de barcos que se olvidan

en una mesa de café

y gentes consagradas a fundirse

bajo la luz ambigua

en la llanura de sus movimientos.

No montan el caballo de los héroes,

pero están convencidos

de su programación,

de sus constituciones y sus leyes

igual que yo creí

en mis novelas de caballería.

El retablo del mundo

sustituye las noches

por la historia medida de las noches,

y la luz de los ojos por la sed de las cámaras,

y la piel por un hueco

que las manos dibujan en el aire.

Exígele a la vida que te enseñe

a distinguir el mar del oleaje

que expulsa los desechos junto a las caracolas.

(García Montero 2006: 544-545) 
El retablo de las maravillas en el que ha mutado «[e]1 retablo del mundo» no solo constituye un guiño al entremés cervantino, sino que sugiere la devaluación del impulso vitalista en un simulacro desvitalizado. El veredicto pesimista solo se redime en parte gracias a la exhortación de la duodécima estrofa, que nos conmina a discriminar lo sustantivo de lo accesorio y a detectar la verdad entre el desfile de las apariencias: «Exígele a la vida que te enseñe / a distinguir el mar del oleaje» ${ }^{21}$.

Sin embargo, la composición no termina con el espejismo del desencanto, sino que plantea la posibilidad de una «cordura rebelde» (Scarano 2006: 658). Ya en uno de sus ensayos, García Montero (2008: 20) afirmaba que las empresas desatinadas de don Quijote no se concibieron para cantar la épica del héroe solitario, sino para censurar un código moral antepuesto a la experiencia particular de la realidad. En las estrofas finales (de la 13 a la 16), el regreso a la aldea de don Quijote reproduce el viaje relatado en la novela, a la vez que propugna un impulso orientado hacia el compromiso colectivo y la entraña solidaria:

\author{
Al llegar a mi aldea \\ quise apretar el campo con los dedos \\ hasta sentir su araña \\ al lado de mi nombre, \\ la tarde que resiste en cada sílaba \\ dorada por la lluvia y el sol de la experiencia.
}

Volver será el oficio del amor,

incluso en un lugar impertinente.

Regresa tú también,

aprieta con las manos el silencio

del último rencor

hasta sentir la caracola

que ha guardado la culpa y la inocencia

junto a la voz del mar,

esta canción añil

de los saludos y el adiós

que todavía compartimos.

Y que tu soledad camine por la casa,

vuelva de cuarto en cuarto

dejándose las luces encendidas,

por si alguien las ve,

y no quiere apagarlas,

y pregunta la historia que han escrito en su rostro,

las huellas de su nombre

vulgar y cotidiano como la rebeldía.

21. Como declaraba Chantal Maillard, «de haber vivido entre nosotros, en el siglo XXI, el personaje cervantino se habría desencantado» (2005: 2-3). 
Como la rebeldía de la gente

que se atreve a vivir

fuera de las haciendas encantadas.

(García Montero 2006: 545-546)

Ese regreso implica la convicción de que aún es posible alzarse en armas contra un presente degradado, aunque ahora quien sostiene esa idea no sea el Caballero de la Triste Figura, sino el hidalgo manchego. Las luces encendidas - metáfora de una razón vigilante - alumbran la penúltima estrofa, en la que se advierte un reflejo especular del comienzo del poema: «Las huellas de su nombre / vulgar y cotidiano como la rebeldía». El cambio en el posesivo («mi nombre» por «su nombre») nos avisa de que el horizonte lírico ha evolucionado desde la afirmación subjetiva hasta la autocrítica (Díaz de Castro 2009: 109). Al fundir en una única silueta al mito (don Quijote), a su identidad secreta (Alonso Quijano) y al referente humano que los crio y juntó (Cervantes) (Scarano 2006: 659), García Montero anticipa una exploración en la conciencia que se desarrollará en obras posteriores ( $c f$. Abril 2015: 149-162). Ejemplos de ello son los axiomas-aforismos que dan título a las piezas de Un invierno propio (2011) o la canción triste, entre el blues y el réquiem, que pauta la desolada cadencia de Balada en la muerte de la poesía (2016).

En contraste con el idealismo intransitivo, el autor apuesta por la restauración del contrato social y renuncia a las supersticiones de nuevo cuño, basadas en la glorificación de los mundos virtuales (Iravedra 2010: 165). Si uno de los objetivos de la poesía de la experiencia fue imponer «distancia crítica ante una subjetividad divinizada en la crisis romántica» (García Montero 1993: 234), «Las confesiones de don Quijote» constituyen una inmejorable oportunidad para rebatir en verso la tesis defendida por Rubén Darío en su «Letanía...», algo que García Montero ya había hecho antes por la vía de la prosa: «Nada más alejado del espíritu cervantino que esa lectura romántica del héroe, condensada en la "Letanía de Nuestro Señor don Quijote", de Rubén Darío, luchador espiritual y solitario contra las convenciones vulgares de la sociedad» (García Montero 1999: 82). La comparación entre el don Quijote de Darío y el Alonso Quijano de García Montero, sintetizada en la siguiente tabla, muestra las diferencias entre ambas composiciones, a tal punto que la de este último podría verse como una perfecta antítesis de la de Darío. Del mismo modo que Cervantes concibió una parodia de las novelas de caballería que acabó quedándosele pequeña, quizá el poema de García Montero deba interpretarse como un intento de invertir irónicamente la simbología mítica vinculada a don Quijote, por más que sus «confesiones» también trasciendan ese propósito inicial. 


\begin{tabular}{|c|c|}
\hline $\begin{array}{l}\text { «Letanía de Nuestro Señor } \\
\text { Don Quijote» }\end{array}$ & $\begin{array}{l}\text { «Las confesiones } \\
\text { de don Quijote» }\end{array}$ \\
\hline Plegaria (coral) & Confidencia (en voz baja) \\
\hline Protagonismo de don Quijote (tú) & Protagonismo de Alonso Quijano (yo) \\
\hline $\begin{array}{l}\text { Heroísmo: } \\
\text { «el paso augusto de tu heroicidad» }\end{array}$ & $\begin{array}{l}\text { Antiheroísmo: } \\
\text { «la nobleza ridícula que yo mismo elegí» }\end{array}$ \\
\hline Divinización / mitificación & Humanización / desmitificación \\
\hline $\begin{array}{l}\text { Idealismo: } \\
\text { «yelmo de ilusión» }\end{array}$ & $\begin{array}{l}\text { Realismo: } \\
\text { «triste ilusión» }\end{array}$ \\
\hline $\begin{array}{l}\text { Enigma: } \\
\text { «que en lo misterioso vi» }\end{array}$ & $\begin{array}{l}\text { Cotidianidad: } \\
\text { «abre el balcón / y asómate a las Ramblas» }\end{array}$ \\
\hline $\begin{array}{l}\text { Rebelión individual: } \\
\text { «[c]aballero errante de los caballeros» }\end{array}$ & $\begin{array}{l}\text { Rebeldía colectiva: } \\
\text { «[c]omo la rebeldía de la gente» }\end{array}$ \\
\hline Destinatario: don Quijote (tú) & Destinatario: lector actual (yo-tú-ellos) \\
\hline
\end{tabular}

Diferencias entre la «Letanía de Nuestro Señor don Quijote», de Rubén Darío, y «Las confesiones de don Quijote», de Luis García Montero.

En definitiva, García Montero culmina el proceso de humanización del Quijote emprendido en la poesía reciente: ahora ya no interesa la energía heroica de don Quijote, sino la humildad cómplice de Alonso Quijano. Encuadrado en un «realismo posmoderno» (Oleza 1996: 39-42), este texto canta a la difícil supervivencia del hombre común que afronta el reto de mirarse al espejo y decir: «Yo sé quién soy».

\section{RECAPITULACIÓN}

Los poemas analizados en estas páginas demuestran la vigencia de la obra cervantina y la liberan de los lastres simbólicos con los que cargó desde que Rubén Darío designara a don Quijote como heredero de Cristo, paladín de la imaginación y rebelde con causa. Frente a la persistencia de esa lectura romántica, a finales del siglo XX y comienzos del siglo XXI predomina una visión prosaica y realista del caballero. En aquellos casos en los que el protagonismo recae en don Quijote, el idealismo, la heroicidad o el redentorismo que se le atribuían en las décadas anteriores se resuelven en una burla antiheroica, ya sea a través de una deformación grotesca (Manuel Vilas) o del diagnóstico clínico de su locura (Felipe Benítez Reyes). Asimismo, la dimensión metafórica de los personajes del Quijote, asociados con los debates identitarios y las esencias espirituales de la españolidad, desaparece progresivamente en un entorno posmoderno que aboga por la universalidad de las criaturas cervantinas, sella su pasaporte de ciudadanos del mundo y los devuelve a la casilla de la literatura. Desde esta perspectiva, don Quijote ha dejado de ser el representante del arrebato justiciero, de la voluntad regene- 
racionista y del empuje revolucionario para reducirse a la condición de un juguete tragicómico que mueve a una sonrisa compasiva. Un paso más allá de esa diatriba contra don Quijote se encuentran aquellas composiciones que apuestan por la razón y por los emblemas de la cordura incluidos en la obra, llámense Aldonza Lorenzo o Alonso Quijano. Si la Dulcinea desencantada de Ana Merino descubre los trampantojos de la ficción, asume su estatuto de invención femenina y esgrime una desafiante voz propia, el Alonso Quijano de García Montero subvierte el individualismo mesiánico de don Quijote para erigirse en portavoz de la ética cívica, la conciencia solidaria y los valores colectivos.

El nuevo pacto de lectura que establece el Quijote con los receptores actuales se sustenta en la humanización de las figuras novelescas, en la faceta cotidiana de sus personalidades y en la adhesión que despiertan sus reflexiones. No cabe duda de que a don Quijote le tocaron vivir malos tiempos para la épica. Los poetas que siguen escribiendo en unos tiempos todavía peores para la lírica ya no aspiran a que sus versos sean «lengua del alma», sino que se conforman con traer al presente a un caballero vestido con vaqueros y a una tropa de ilustres secundarios a los que la historia ha convertido en patrimonio de la humanidad.

\section{BIBLIOGRAFÍA CITADA}

Abril, Juan Carlos (2015). «Dos momentos decisivos en la poesía de Luis García Montero», Signa. 24, pp. 149-162. https://doi.org/10.5944/signa.vol24.2015.14710.

Alarcos Martínez, Miguel (2007). «Materiales cervantinos del Quijote en la poesía de Blas de Otero: ¿lectura poética cervantista o quijotista?», en Emilio Martínez Mata (ed.), Cervantes y "El Quijote». Actas del Coloquio Internacional. Madrid: Arco / Libros, pp. 337-354.

Andújar Almansa, José ([2003] 2011). «La lucidez y la quimera», en Los paisajes magnéticos. Granada: Diputación de Granada, pp. 183-244.

Benítez Reyes, Felipe (1999). «La crueldad aplicada a unos muñecos», en José Luis García Martín (ed.), Nuevas visiones del Quijote. Oviedo: Nobel, pp. 23-47.

Carilla, Emilio (1951). «Don Quijote, Dios y santo», en Cervantes y América. Buenos Aires: Universidad de Buenos Aires, pp. 61-70.

Cernuda, Luis (1974). Poesía completa. Barcelona: Barral.

Cervantes Saavedra, Miguel de ([1605 y 1615] 1991). El ingenioso hidalgo don Quijote de la Mancha. Madrid: Castalia, 2 vols. Edición de Luis Andrés Murillo.

Cervantes Saavedra, Miguel de (1994). Obra completa 2. Galatea. Novelas ejemplares. Persiles y Sigismunda, ed. Florencio Sevilla Arroyo y Antonio Rey Hazas. Alcalá de Henares: Centro de Estudios Cervantinos.

Close, Anthony (2005). La concepción romántica del Quijote. Barcelona: Crítica.

Darío, Rubén ([1890 y 1905] 1995). Azul... / Cantos de vida y esperanza, ed. José María Martínez. Madrid: Cátedra.

Díaz de Castro, Francisco (2009). «Continuidad y cambio en la poética reciente de Luis García Montero», en Juan Carlos Abril y Xelo Candel Vila (eds.), El romántico ilustrado. Imágenes de Luis García Montero. Sevilla: Renacimiento, pp. 105-116. 
Díez de Revenga, Francisco Javier (2005). «Poesía y mito: la recepción de don Quijote en la lírica de la Edad de Plata», Príncipe de Viana. 236, pp. 713-726.

García, Miguel Ángel (2007). «De Lorca a don Quijote. Historia, Historia de la Literatura y poesía en Luis García Montero», Paraíso. Revista de Poesía. 2, pp. 49-59.

García Jambrina, Luis (2005). «Cuatro sonetos quijotescos dedicados a Eulalio Ferrer», Boletín de la Biblioteca Menéndez Pelayo. 81, pp. 175-183,

García Montero, Luis (1993). Confesiones poéticas. Granada: Diputación de Granada.

García Montero, Luis (1996). «Una musa vestida con vaqueros», en Aguas territoriales. Valencia: Pre-Textos, pp. 69-76.

García Montero, Luis (1999). «La pluma en la oreja», en José Luis García Martín (ed.), Nuevas visiones del Quijote. Oviedo: Nobel, pp. 75-90.

García Montero, Luis (ed.) (2005). La poesía, señor hidalgo... Antología de poemas cervantinos. Madrid: Visor.

García Montero, Luis (2006). Poesía (1980-2005). Barcelona: Tusquets.

García Montero, Luis (2008). Inquietudes bárbaras. Barcelona: Anagrama.

García Sánchez, Jesús (ed.) (2005). Visiones del Quijote desde la crisis española de fin de siglo. Madrid: Visor.

González, Ángel ([2002] 2005). «Viaje por los alrededores de Don Quijote», en La poesía y sus circunstancias. Barcelona: Seix Barral, pp. 27-40.

Grandes, Almudena (1999). «Con esos latinicos y otros tales... Miguel de Cervantes o la conciencia de un narrador moderno», en José Luis García Martín (ed.), Nuevas visiones del Quijote. Oviedo: Nobel, pp. 91-114.

Iravedra, Araceli (2010). «"Partidario de la felicidad”: el horizonte de la Ilustración en la poesía de Luis García Montero», Cuadernos Dieciochistas. 11, pp. 153-175.

Juaristi, Jon (1994). «El pacto realista», Ínsula. 565, pp. 25-26.

Langbaum, Robert ([1958] 1996). La poesía de la experiencia. El monólogo dramático en la tradición literaria moderna, ed. Julián Jiménez Heffernan. Granada: Comares.

Maillard, Chantal (2005). «El desencanto del Quijote», en VV. AA., Encuentros en Verines 2005. La herencia del Quijote y de Cervantes en la literatura actual. Accesible en: $<$ http://www.mecd.gob.es/lectura/pdf/267.pdf $>$. Fecha de acceso: 04/02/2017.

Merino, Ana (2006). Compañera de celda. Madrid: Visor.

Morón Olivares, Eva (2007). «... De tu lanza en la pluma. La recepción del Quijote en la poesía española contemporánea», en Klaus-Dieter Ertler y Alejandro Rodríguez Díaz (eds.), El Quijote hoy. La riqueza de su recepción. Madrid / Frankfurt: Iberoamericana / Vervuert, pp. 165-183.

Oleza, Joan (1996). «Un realismo posmoderno», Ínsula. 589-590, pp. 39-42.

Orihuela, Antonio (2016). «Contra el compromiso único», blog Voces del Extremo. Documentos de pensamiento radical. Accesible en: $<$ http://vocesdelextremopoesia.blogspot. com/2016/05/contra-el-compromiso-unico.html>. Fecha de acceso: 05/02/2017.

Palomo Alepuz, Laura (2016). «"Letanía de Nuestro Señor don Quijote”: sacralización del hidalgo manchego», Contrapunto. Publicación de Crítica e Información Literaria. 26, pp. 73-83.

Scarano, Laura (2004). Luis García Montero: la escritura como interpelación. Granada: Atrio.

Scarano, Laura (2006). «Alonso Quijano o el elogio de la cordura (Las confesiones de don Quijote de Luis García Montero)», en Alicia Parodi, Julia D’Onofrio y Juan Diego Vila (eds.), «El Quijote» en Buenos Aires. Lecturas cervantinas en el cuarto centenario. Buenos Aires: Universidad de Buenos Aires, pp. 655-660.

Trapiello, Andrés (2004). Al morir don Quijote. Barcelona: Destino. 
Valle-Inclán, Ramón María del ([1924] 1985). Luces de bohemia. Madrid: Espasa-Calpe. Edición de Alonso Zamora Vicente.

Van-Halen, Juan (2005). «Reflejos del Quijote en la poesía», en Nicasio Salvador Miguel y Santiago López-Ríos (eds.), El Quijote desde el siglo XXI. Alcalá de Henares: Centro de Estudios Cervantinos, pp. 123-131.

Varela Olea, Juan (2003). Don Quijote, mitologema nacional (Literatura y política entre la Septembrina y la II República). Alcalá de Henares: Centro de Estudios Cervantinos.

Vilas, Manuel (1998). Las arenas de Libia. Madrid: Huerga y Fierro.

Vilas, Manuel (2005). «El Quijote hoy en la cultura española», en VV. AA., Encuentros en Verines 2005. La herencia del Quijote y de Cervantes en la literatura actual. $<\mathrm{http}: / /$ www.mecd.gob.es/lectura/pdf/258.pdf>. Fecha de acceso: 04/02/2017.

Vilas, Manuel (2016). Poesía completa (1980-2015). Madrid: Visor.

Recibido: 13 de febrero de 2017 Aprobado: 28 de agosto de 2017 